\title{
Microstructural Investigation of Nanocrystalline Hydrogen-Storing Mg-Titanate Nanotube Composites Processed by High-Pressure Torsion
}

\author{
Marcell Gajdics ${ }^{1}$, Tony Spassov ${ }^{2}$, Viktória Kovács Kis ${ }^{3,4}{ }^{\circledR}$, Ferenc Béke ${ }^{5}$, Zoltán Novák ${ }^{5}$, \\ Erhard Schafler ${ }^{6}$ and Ádám Révész ${ }^{1, *}$ \\ 1 Department of Materials Physics, Eötvös University, P.O.B. 32, H-1518 Budapest, Hungary; \\ gajdicsmar@caesar.elte.hu \\ 2 Department of Chemistry, University of Sofia “St.K1.Ohridski”, 1164 Sofia, Bulgaria; nhtts@chem.uni-sofia.bg \\ 3 Center of Energy Research, Hungarian Academy of Sciences, H-1121 Budapest, Hungary; \\ kis.viktoria@energia.mta.hu \\ 4 Institute of Environmental Sciences, University of Pannonia, Egyetem u. 10., 8200 Veszprem, Hungary \\ 5 Department of Organic Chemistry, Eötvös University, P.O.B. 32, H-1518 Budapest, Hungary; \\ bekeferi@hotmail.com (F.B.); novak@elte.hu (Z.N.) \\ 6 Faculty of Physics, University of Vienna, A-1090 Vienna, Austria; erhard.schafler@univie.ac.at \\ * Correspondence: reveszadam@ludens.elte.hu
}

Received: 23 December 2019; Accepted: 16 January 2020; Published: 23 January 2020

\begin{abstract}
A high-energy ball milling and subsequent high-pressure torsion method was applied to synthesize nanocrystalline magnesium samples catalyzed by $\mathrm{TiO}_{2}$ or titanate nanotubes. The microstructure of the as-milled powders and the torqued bulk disks was characterized by X-ray diffraction. The recorded diffractograms have been evaluated by the convolutional multiple whole profile fitting algorithm, which provided microstructural parameters (average crystal size, crystallite size distribution, average dislocation density). The morphology of the nanotube-containing disks has been examined by high-resolution transmission electron microscopy. The effect of the different additives and preparation conditions on the hydrogen absorption behavior was investigated in a Sieverts'-type apparatus. It was found that the ball-milling route has a prominent effect on the dispersion and morphology of the titanate nanotubes, and the absorption capability of the Mg-based composite is highly dependent on these features.
\end{abstract}

Keywords: ball milling; high-pressure torsion; magnesium; titanate nanotubes; hydrogen storage

\section{Introduction}

The coupling between continuing growth of the world's population and industrialization means that the transportation segment of the economy is responsible for significant part of petroleum consumption, and accordingly transportation is one of the main source of global $\mathrm{CO}_{2}$ emission [1]. In addition, the world's energy consumption is expected to be doubled by 2050, which requires the introduction of alternative energy sources to the energy grid [2]. Even though these alternative renewable sources are not competitive with fossil fuels at the moment [3], hydrogen as a secondary energy carrier has gained increasing attention in the last decade; however, significant technical and economical challenges, such as efficient production and storage need to be solved [4]. It has been reported that hydrogen can be stored either in molecular form by physisorption on the surface of carbon-based materials [5,6], or in atomic form by chemisorption in metal-based compounds [7,8].

As has been extensively studied, absorption of hydrogen in metal-based compounds results in higher energy density and safety when compared to gas storage of molecular hydrogen or 
low-temperature liquefaction [7]. Among the vast variety of chemisorbing solid-state storage systems, magnesium-based materials have been extensively and systematically studied owing to their high energy density up to $2600 \mathrm{Wh} / \mathrm{kg}$ or $3700 \mathrm{Wh} / \mathrm{l}$, relatively low cost, non-toxic nature, and abundance which allows them to be considered as a potential candidate for future applications [8-11]. On the other hand, the poor thermodynamics, high thermal stability of $\mathrm{MgH}_{2}$ and the sluggish kinetics of dehydrogenation below $300{ }^{\circ} \mathrm{C}$ are significant obstacles which still hinder the practical utilization of the Mg-H system [11-13].

In order to overcome these limitations of Mg-based systems, nanotechnology and nanoscale material design with different dimensionalities have been in the forefront of recent research [14,15]. Among the huge number of different processing techniques, nanocrystallization of metallic powders by high energy ball milling (HEBM) has been extensively applied world-wide to reduce the crystallite size down to the nanometric regime [10,11,15-18]. Due to improved hydrogen diffusion length created by the lattice defects and increased volume fraction of grain boundaries during the severe plastics deformation (SPD), these nanocrystalline powders exhibit significantly improved hydrogen sorption kinetics [18-20].

Parallel to HEBM, recently other SPD-based processing techniques resulting in massive bulk samples have been applied to magnesium-based alloys. Among these techniques, high-pressure torsion (HPT) exhibits the largest equivalent strain, coupled with advantages such as less energy consumption, less surface oxidation and smaller safety concerns [21]. Separately, HPT provides an opportunity to process materials at room temperature with low formability such as magnesium [22]. As has been shown, the uniaxial pressure combined with simultaneous heavy shear deformation during the HPT torsional straining can significantly enhance the hydrogen sorption properties due to the high volume fraction of grain boundaries and large defect density [23-27]. In addition, the nanostructure generated by HPT is practically preserved through several subsequent hydrogenation/dehydrogenation reactions resulting in a significant cyclic stability of nanocrystalline Mg-based alloys [28,29].

Besides nanocrystallization by the top-down approach, the hydrogen storage properties of Mg-based materials can be further enhanced by the addition of catalysts such as different transition metals [30-34], transition metal oxides [17,20,34-36] and carbon-based materials, such as carbon nanotubes [37-41]. Among various transition metal oxide additives, $\mathrm{TiO}_{2}$ has proved to be one of the most effective in improving the hydrogen sorption kinetics of $\mathrm{MgH}_{2}$ [38,42-44]. It was shown that upon mixing $\mathrm{TiO}_{2}$ to $\mathrm{MgH}_{2}$ by means of $\mathrm{HEBM}$, the desorption temperature decreased significantly [44,45]. According to $\mathrm{M}$. Chen and coworkers, the dehydrogenation of $\mathrm{MgH}_{2}$ takes place at a temperature $80{ }^{\circ} \mathrm{C}$ lower in the presence of $\mathrm{TiO}_{2}$ catalyst than without it [45]. The reduction of the kinetic barrier for hydrogen release was demonstrated quantitatively by M. Polanski and J. Bystrzycki, and the calculated desorption activation energy was decreased from 150 to $94 \mathrm{~kJ} / \mathrm{mol}$ upon $\mathrm{TiO}_{2}$ addition [44]. Starting from $\mathrm{TiO}_{2}$ powder, Jardim P.M. and co-workers prepared titanate nanotubes via hydrothermal method for the catalysis of $\mathrm{MgH}_{2} \mathrm{H}$-sorption reactions. It was shown that the titanate nanotubes can also improve the desorption kinetics of $\mathrm{MgH}_{2}$, as they act as diffusion channels for hydrogen atoms, similar to carbon nanotubes [46].

In a recent work we investigated the influence of simultaneous mixing of transition metal oxide and carbon nanotube catalysts on the hydrogen storage performance of severely deformed nanocrystalline magnesium [40]. The idea of the current research is to substitute these two kinds of catalyst by applying only metal oxide-based nanotubes prepared from $\mathrm{TiO}_{2}$. The microstructure morphology and nanocrystalline $\mathrm{Mg}$-based composite materials containing titanate nanotube additive prepared by the combined method of HEBM and HPT will be demonstrated. For comparison, a magnesium sample catalyzed with $\mathrm{TiO}_{2}$ powder was also synthesized. We also present the effect of the preparation conditions on the microstructure, morphology and hydrogen storage properties of these materials. 


\section{Materials and Methods}

\subsection{Sample Preparation}

\subsubsection{Preparation of Titanate Nanotubes}

Titanate nanotubes (TN) were prepared via the microwave-assisted hydrothermal method $[47,48]$. The starting material was anatase $\mathrm{TiO}_{2}$ powder (supplied by Reanal; purity $99.9 \%$ ) which was filtered using cotton wool and distilled water. $0.35 \mathrm{~g}$ of filtered $\mathrm{TiO}_{2}$ powder was mixed with $7 \mathrm{~mL}$ of $\mathrm{NaOH}$ aqueous solution $(10 \mathrm{M})$, the suspension was stirred ultrasonically for $20 \mathrm{~min}$. The mixture was then heated to $135{ }^{\circ} \mathrm{C}$ for $8 \mathrm{~h}$ in a closed SiC vial by microwave irradiation using a Monowave 300 microwave reactor in the presence of continuous stirring. The product was then dispersed in $300 \mathrm{~mL}$ distilled water and centrifuged for $5 \mathrm{~min}$ at $1500 \mathrm{RPM}$, this procedure was repeated two more times. The remaining material was dried overnight at $60^{\circ} \mathrm{C}$. As seen in Figure 1, the as-prepared titanate nanotubes are multi-wall tubes, with a length ranging from $40 \mathrm{~nm}$ to several hundreds of nanometers and their diameter is in the range of $10 \mathrm{~nm}$.

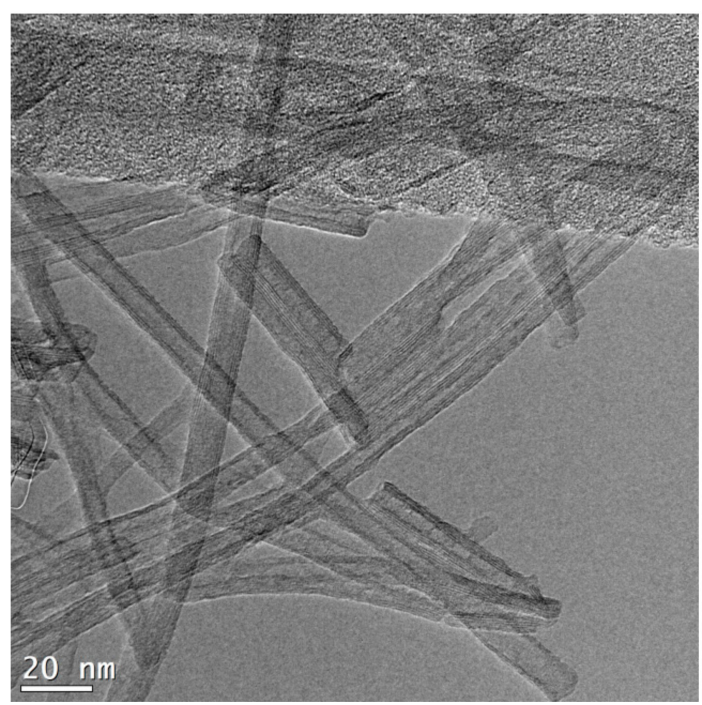

Figure 1. Transmission electron microscopy (TEM) micrograph of the as-prepared titanate nanotubes.

\subsubsection{Preparation of Magnesium-Titanate Nanotube Composites}

$\mathrm{Mg}-\mathrm{TN}$ composites were prepared by mixing Mg powder (supplied by Sigma-Aldrich; purity $99.9 \%$, initial powder particle size $\sim 100 \mu \mathrm{m}$ ), $5 \mathrm{wt} . \%$ titanate nanotube (described in the previous section) and $3 \mathrm{~mL}$-hexane. The resulting suspension was ball-milled in a stainless steel vial (volume: $65 \mathrm{~mL}$ ) using a SPEX 8000M Mixer Mill operating at 1425 RPM. For all samples, 10 stainless steel balls (1/4 in.) were used, thus the ball-to-powder weight ratio was 10:1. Two milling routes were applied:

1. all the constituents were milled together for $3 \mathrm{~h}$ (denoted as MgTN_3h);

2. the magnesium powder was pre-milled for $2.5 \mathrm{~h}$ in hexane before the titanate nanotubes were added for an additional $0.5 \mathrm{~h}$ milling (denoted as MgTN_0.5h).

For comparison, a $\mathrm{Mg}-\mathrm{TiO}_{2}$ composite was also prepared, using $5 \mathrm{wt} . \% \mathrm{TiO}_{2}$ commercial powder via wet ball-milling in $3 \mathrm{~mL}$-hexane (denoted as $\mathrm{MgTiO} 2 \_3 \mathrm{~h}$ ). Here, milling route \#1 was applied, i.e., the materials were milled together for $3 \mathrm{~h}$, other milling parameters were the same as above. Sample handling was carried out in a glove box and HEBM was processed in argon atmosphere in order to minimize the oxidation of the powder samples.

The as-milled powders were pre-compacted into pellets with a diameter of $8 \mathrm{~mm}$ and height of $0.8 \mathrm{~mm}$ under $200 \mathrm{MPa}$ of hydraulic pressure. High-pressure torsion of these pellets was carried out in 
air, under an applied pressure of $4 \mathrm{GPa}$ at room temperature. $\mathrm{N}=3$ and $\mathrm{N}=10$ whole revolutions were performed for all types of powder samples with an angular speed of $\omega=0.2$ revolution $/ \mathrm{min}$. These disk shape samples will be denoted as: MgTN_3h_N3, MgTN_3h_N10, MgTN_0.5h_N3, MgTN_0.5h_N10, MgTiO2_3h_N3 and MgTiO2_3h_N10.

\subsection{Microstructural Characterization}

\subsubsection{X-ray Diffraction (XRD)}

The overall microstructure of the powders and HPT-disks was examined by X-ray powder diffraction (XRD). The measurements were carried out on a Rigaku SmartLab diffractometer in $\theta-2 \theta$ geometry using $\mathrm{Cu}-\mathrm{K} \alpha$ radiation. The data were collected from $20^{\circ}$ to $75^{\circ}$ with a step size of $0.01^{\circ}$. The recorded powder diffraction patterns have been evaluated by the Williamson-Hall method [49]. The average crystallite size $\left(D_{\mathrm{WH}}\right)$ and the square root of the mean square strain $\left(\left\langle\varepsilon^{2}\right\rangle^{1 / 2}\right)$ can be determined from the positions and widths of the Bragg reflections according the following equation [49]:

$$
\Delta \mathrm{K}=0.9 / \mathrm{D}_{\mathrm{WH}}+\mathrm{A}\left\langle\varepsilon^{2}\right\rangle^{1 / 2} \mathrm{~K}
$$

where $K=2 \sin \theta / \lambda$ and $\Delta K=2 \cos \theta(\Delta \theta) / \lambda$. Here $\theta$ is the Bragg angle, $\Delta \theta$ denotes the half of the full width at half maximum of the crystalline peaks, $\mathrm{A}$ is geometrical constant, usually taken as $\mathrm{A}=1$ and $\lambda$ is the wavelength of the radiation $(\lambda=0.154 \mathrm{~nm})$.

In order to reveal the possible differences in microstructure along the radius of the HPT disks, a Rigaku rotating anode high resolution $\mathrm{X}$-ray diffraction instrument with $\mathrm{Cu}-\mathrm{K} \alpha$ radiation was also applied. The spot size of the X-ray beam was $1 \mathrm{~mm} \times 0.1 \mathrm{~mm}$ which enabled us to characterize separate regions with different ultimate strain along the disks, i.e., center, half-radius and edge regions were studied. The operating voltage and current were $40 \mathrm{kV}$ and $80 \mathrm{~mA}$, respectively. For detection of the diffracted X-ray photons, image plates (IP) were used at a distance of $200 \mathrm{~mm}$ from the sample.

The XRD profiles measured by the rotating anode instrument have been evaluated by the convolutional multiple whole profile (CMWP) fitting algorithm which incorporates the direct fit of the whole measured diffraction profile by the sum of theoretically constructed profile functions, background and measured instrumental profiles [50]. In brief, the contribution of lattice strain and coherently scattering domains on peak broadening can be separated on the basis of their different diffraction order dependence. The applied profile functions are generated for each Bragg-reflection of each crystalline phase as the inverse Fourier transform of the product of the size and strain Fourier coefficients providing both the strain and size parameters of the microstructure [51]. In this model, it is assumed that the crystallites have a lognormal size distribution:

$$
\mathrm{G}(\mathrm{x})=(2 \pi)^{-1 / 2} \sigma^{-1} \mathrm{x}^{-1} \exp \left[-(\ln (\mathrm{x} / \mathrm{m}))^{2} / 2 \sigma^{2}\right]
$$

where $\sigma$ and $m$ are the variance and median of the histogram, respectively. As a result, the average size of the coherently scattering domains can be given as

$$
\mathrm{D}_{\mathrm{CMWP}}=\mathrm{m} \exp \left(3.5 \sigma^{2}\right)
$$

The CMWP algorithm also provides the strain parameters, i.e., the average dislocation density ( $\rho$ ) can also be determined [50].

\subsubsection{Transmission Electron Microscopy (TEM)}

Local structure of the HPT-disks were characterized by high-resolution transmission electron microscopy (HR-TEM) using a JEOL JEM 3010 electron microscope equipped with a $\mathrm{LaB}_{6}$ cathode and working at $300 \mathrm{keV}$ (point resolution $1.7 \AA$ ). Sample preparation for TEM investigations was carried 
out with focused ion beam (FIB) milling, i.e., a lamella was cut out from the disk (close to the edge) and subsequently thinned in a FEI QUANTA 3D scanning electron microscope equipped with FIB.

\subsection{Hydrogen Storage Experiments}

The hydrogen storage properties of the samples were investigated using a home-made Sieverts' type apparatus. Isothermal absorption and desorption measurements were performed at $573 \mathrm{~K}$, with an initial hydrogen pressure of $1 \mathrm{MPa}$ and $1 \mathrm{kPa}$, respectively. The actual measurements were carried out after two full hydrogenation-dehydrogenation cycles. For all the experiments, the whole HPT-disks $(\sim 80-90 \mathrm{mg}$ each) were used as prepared.

\section{Results and Discussion}

The XRD patterns of the as-milled composites along with the commercial $\mathrm{Mg}$ and $\mathrm{TiO}_{2}$ powders and the as-prepared titanate nanotubes are presented in Figure 2. As is apparent, the main constituent phase is hexagonal Mg (JCPDS: 00-035-0821) for all composite samples. In addition, Bragg peaks of $\mathrm{TiO}_{2}$ (JCPDS: 01-084-1285) can also be recognized for the MgTiO2_3h powder. On the other hand, no reflection corresponding to titanate nanotubes can be visualized in either nanotube containing samples (MgTN_0.5h and MgTN_3h), which might be attributed to the low crystallinity of the additive or to a possible partial amorphization, which can occur during the HEBM process when the milling balls impact the tubes. At the same time, a broad peak of MgO (JCPDS: 45-0946) at around $2 \theta=43 \mathrm{deg}$ is present for all the as-milled powders.

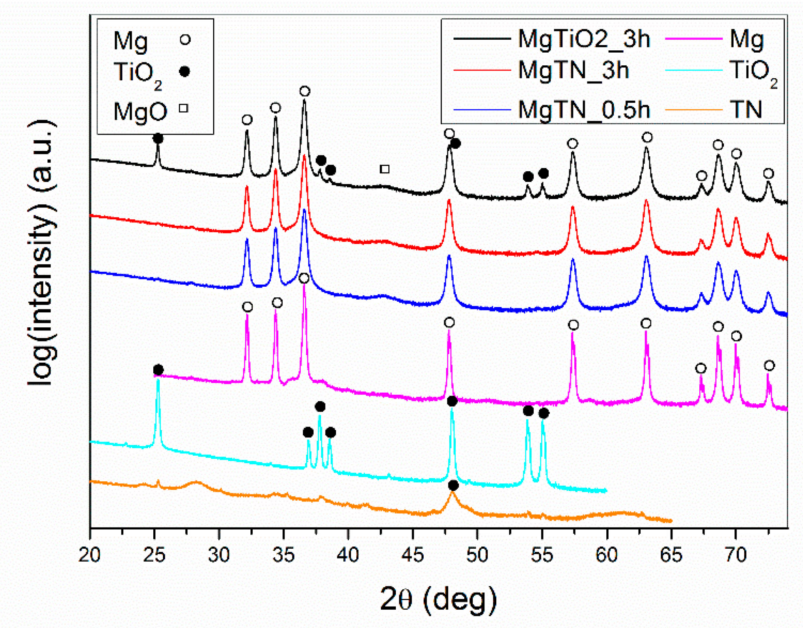

Figure 2. X-ray powder diffractograms of commercial $\mathrm{Mg}$, $\mathrm{TiO}_{2}$ powders, as-prepared titanate (TN) nanotubes and the as-milled MgTiO2_3h, MgTN_0.5h and MgTN_3h composites.

Based on preliminary experiments, we chose two rotation numbers $\mathrm{N}=3$ and $\mathrm{N}=10$ for further processing the compacted pellets by HPT. The corresponding powder diffractograms averaging the X-ray scattering from the whole disks indicate only a slight deviation compared to those of the as-milled powders (Figure 3), i.e., all patterns are dominated by the crystalline peaks of hexagonal $\mathrm{Mg}$. It is also noted that the intensity of the $\mathrm{MgO}$ phase remains practically the same after the HPT-processing carried out under air. As one can also notice, the peaks of $\mathrm{TiO}_{2}$ are still visible after the HPT deformation (MgTiO2_3h_N3 and MgTiO2_3h_N10 samples). 


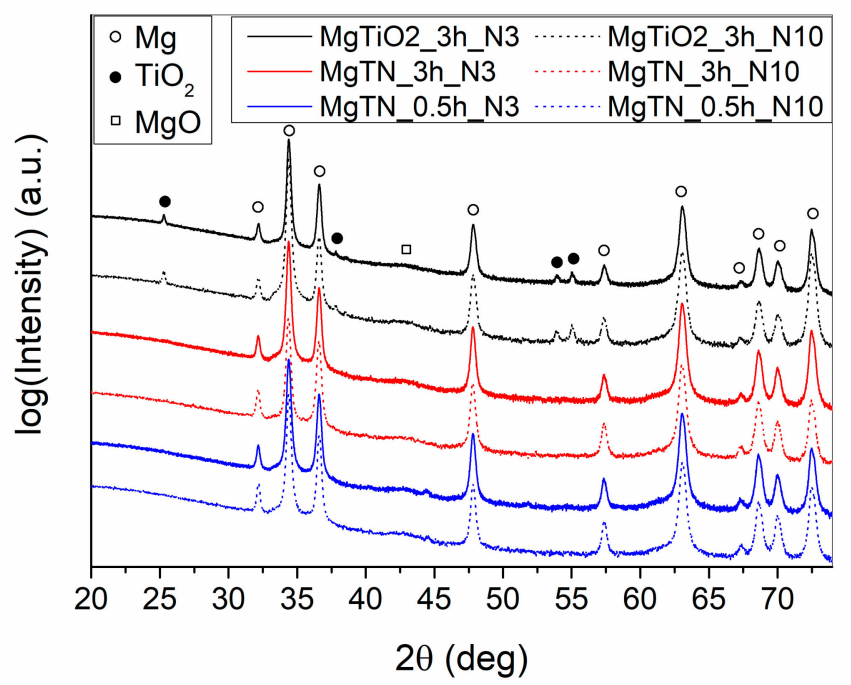

Figure 3. X-ray diffraction (XRD) patterns of the high-pressure torsion (HPT) processed $\mathrm{Mg}$ composites after $\mathrm{N}=3$ and $\mathrm{N}=10$ revolutions.

The relative intensities of the $\mathrm{Mg}$ peaks vary considerably between specimens prepared by the different routes (see Table 1). Notably, the intensity ratio of the (101) and (002) Mg reflections can be used as a measure of texture generated during deformation processes [40]. As one can recognize, the HEBM procedure results in some reduction of the $\mathrm{I}(101) / \mathrm{I}(002)$ ratio, as compared to the commercial $\mathrm{Mg}$ powder (initially I $(101) / \mathrm{I}(002)=3.04)$. However, a more prominent change can be observed as a result of the torsion process, i.e., $\mathrm{I}(101) / \mathrm{I}(002)$ decreases down to the $0.3-0.4$ interval even after $\mathrm{N}=$ 3 whole revolutions. Interestingly, additional shear deformation $(\mathrm{N}=10)$ does not further alter the texture of the $\mathrm{Mg}$ phase for the MgTN_0.5h type sample, meanwhile the I(101)/I(002) ratio slightly increase and decrease for the MgTN_3h and MgTiO2_3h type samples, respectively.

Table 1. Intensity ratios of the (101) and (002) Mg reflections for the different composite powders and HPT disks.

\begin{tabular}{cccc}
\hline Sample & Powder & HPT $(\mathbf{N}=3)$ & HPT $(\mathbf{N}=\mathbf{1 0})$ \\
\hline MgTiO2_3h & 2.11 & 0.28 & 0.12 \\
MgTN_3h & 1.86 & 0.28 & 0.54 \\
MgTN_0.5h & 2.32 & 0.39 & 0.33 \\
\hline
\end{tabular}

The average grain size values $\left(D_{\mathrm{WH}}\right)$ and the square root of the mean square strain $\left(\left\langle\varepsilon^{2}\right\rangle^{1 / 2}\right)$ for all the as-milled powders and HPT-disks were obtained by the Williamson-Hall analysis and are plotted in Figure $4 \mathrm{a}, \mathrm{b}$, respectively. As can be seen, some variation takes place in the $\mathrm{D}_{\mathrm{WH}}$ values $(65-85 \mathrm{~nm}$ range) of hexagonal magnesium when it is milled together with different additives. The HPT-deformation results in some further nanocrystallization, i.e., the decrease of the average grain size for the $\mathrm{TiO}_{2}$ containing composite (MgTiO2_3h) and for the sample MgTN_3h occurs between $\mathrm{N}=3$ and $\mathrm{N}=10$ revolutions $\left(\mathrm{D}_{\mathrm{WH}} \sim 55-60 \mathrm{~nm}\right)$. A similar reduction can be observed in case of the MgTN_0.5h composite, however, this change occurs already during the first 3 revolutions. Rather similar trends can be visualized for the mean square strain (see Figure $4 \mathrm{~b}$ ). As the powders have been subjected to HEBM, a $\left\langle\varepsilon^{2}\right\rangle^{1 / 2} \sim 0.37 \%-0.45 \%$ strain already develops as a result of the severe plastic deformation generated by the colliding balls. As HPT is introduced, a general decrease for all the composites can be recognized after $\mathrm{N}=10$ revolutions, reaching an ultimate value of $\left\langle\varepsilon^{2}\right\rangle^{1 / 2} \sim 0.35 \%$, corresponding to some kind of strain release during the shear deformation. It is also noted that a slight increase can be observed of the MgTN_3h_N3 disk. 

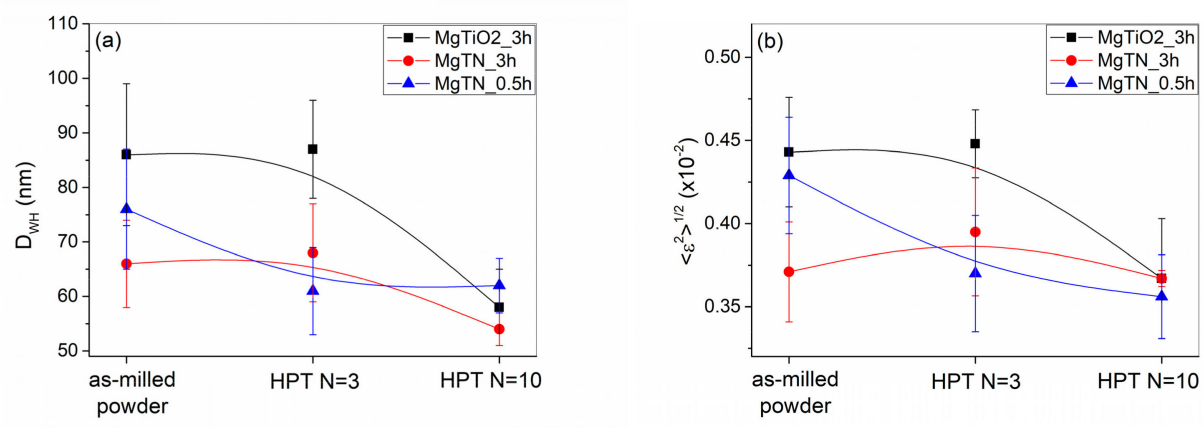

Figure 4. Average crystallite size $\mathrm{D}_{\mathrm{WH}}(\mathbf{a})$ and square root of the mean square strain $\left\langle\varepsilon^{2}\right\rangle^{1 / 2}(\mathbf{b})$ of the hexagonal Mg phase for the as-milled powders and HPT-disks obtained by the Williamson-Hall method.

As the HPT procedure imposes inhomogeneous strain along the radius of the disk, smaller revolution numbers can result in a deformation-dependent structure [52] and mechanical properties [53], however, larger rotations can homogenize the material [54,55]. Therefore, we chose the disks that performed for $\mathrm{N}=3$ rotations for subsequent investigations.

In order to explore the radius dependent microstructure, position sensitive high resolution XRD was carried out on different parts of the disks. Figure 5 shows one set of diffractograms taken at different positions of the MgTN_3h_N3 disk. As seen, the XRD profiles are qualitatively similar, i.e., hexagonal $\mathrm{Mg}$ reflections dominate the patterns. These high-resolution XRD profiles were analyzed by the CMWP method in order to obtain several microstructural parameters. A typical example of the measured and fitted profiles together with the difference plot corresponding to the half radius of the MgTN_3h_N3 sample unambiguously confirms that the numerical algorithm has satisfactorily converged (see Figure 6).

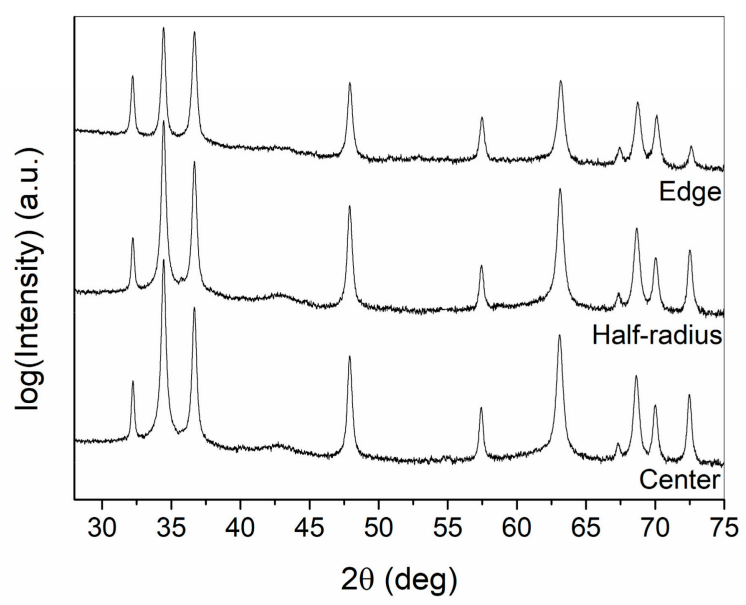

Figure 5. High resolution XRD patterns of the MgTN_3h_N3 sample taken at the center, half radius and edge of the disk.

Based on the evaluation of the line profiles by the CMWP method, the average coherently scattering crystallite size of $\mathrm{Mg}$ phase can be determined as shown in Figure $7 \mathrm{a}$. In general, the $\mathrm{D}_{\mathrm{CMWP}}$ values are fairly constant along the radius for all the disks after $\mathrm{N}=3$ revolutions. Nevertheless, the type of additive has an influence on the crystallite size, i.e., the addition of titanate nanotubes results in smaller $\mathrm{D}_{\mathrm{CMWP}}$ of $\mathrm{Mg}$ than in case of $\mathrm{TiO}_{2}$ catalyst, in accordance with Figure 4a. In spite of the apparent invariance of the average crystallite size along the disk radius, some microstructural differences between the different sectors can be identified. Using the $m$ and $\sigma$ parameters determined from the fitting procedure, the $\mathrm{G}(\mathrm{x})$ lognormal size-distribution functions can be generated (Figure $7 \mathrm{~b}$ ). In the case of the MgTN_3h_N3 disk, the histograms are markedly different for the edge region and for the rest of the disk, i.e., the distribution has smaller median, but larger variance corresponding to a 
more homogeneous nanostructure at the perimeter of the specimen, despite the rather similar average crystallite size values. Similar tendency was observed for the other two disks processed for $\mathrm{N}=3$ turns. Figure 7c presents the dislocation density values across the disk radius after $\mathrm{N}=3$ revolutions. For the MgTiO2_3h_N3 and the MgTN_3h_N3 samples, the $\rho$ values are practically constant throughout the disk $\left(1.7 \cdot 10^{15} \mathrm{~m}^{-2}\right.$ and $2 \cdot 1 \cdot 10^{15} \mathrm{~m}^{-2}$ respectively) which clearly indicates that the dynamic equilibrium between dislocation generation and annihilation is already present even after $\mathrm{N}=3$ rotations. Slightly different behavior can be seen for the MgTN_3h_N3 specimen, i.e., the center of the disk exhibits somewhat lower dislocation density than the rest of the disk.

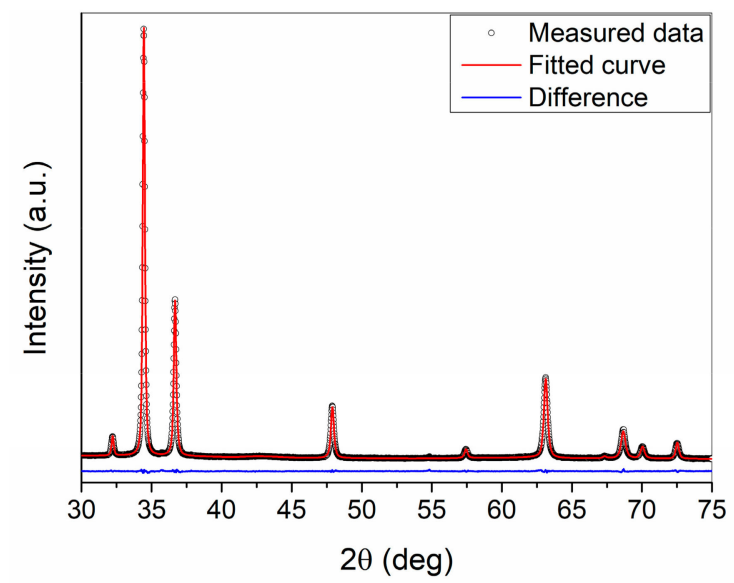

Figure 6. XRD profile of the MgTN_3h_N3 sample (at half radius) fitted by the convolutional multiple whole profile (CMWP) method.

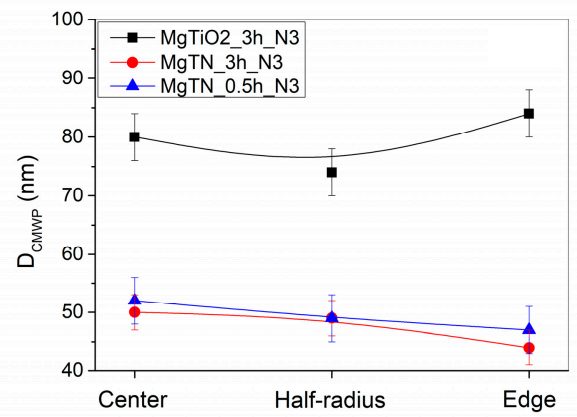

(a)

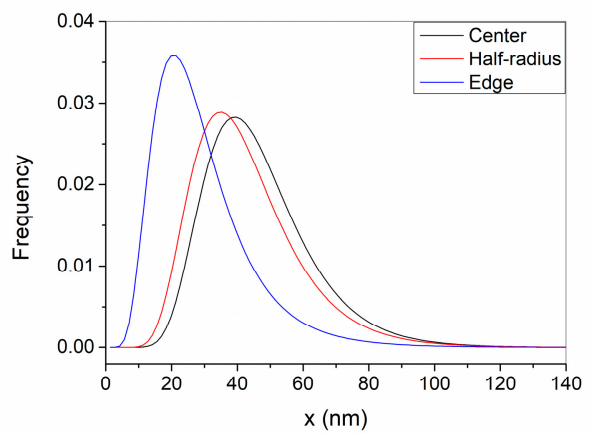

(b)

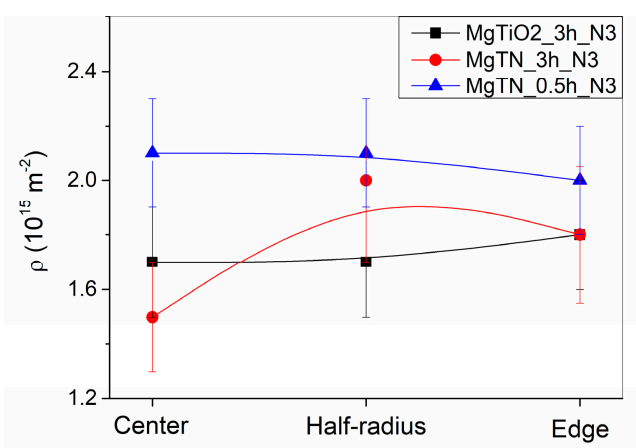

(c)

Figure 7. Microstructural parameters obtained by the CMWP analysis of the Mg-based disks $(\mathrm{N}=3)$ along their radius. Average crystallite sizes (a), lognormal size-distribution functions of MgTN_3h_N3 (b) and average dislocation densities (c). 
For local structural and morphological analysis, transmission electron microscopy was carried out (Figure 8). The low magnification micrograph of the MgTN_0.5h_N3 sample presents inhomogenities in the HPT-disk as several darker regions can be recognized on the lamella (Figure 8a). An enlarged view, Figure $8 \mathrm{~b}$, shows one of these areas where straight bundles of nanotubes can be recognized along with some amorphous-like regions. Noticeably different features can be identified for the MgTN_3h_N3 disk (Figure 8c,d). On the lower magnification image similar inhomogenities can be seen as for the MgTN_0.5h_N3 disk (Figure 8c), however, these inhomogenities are finer and their density is significantly higher compared to Figure $8 \mathrm{a}$. The better distribution of the nanotube additive material is not surprising due to the longer milling time. Closer examination again proves that the darker areas contain titanate nanotubes (see Figure $8 \mathrm{~d}$ ), nevertheless the $3 \mathrm{~h}$ of milling partially destroys the tube structure as significantly amorphized regions can be identified in the vicinity of the tubes. It is noteworthy that the remaining nanotubes are considerably shorter and more curved than the fairly straight and mostly intact nanotubes of MgTN_0.5h_N3 sample.
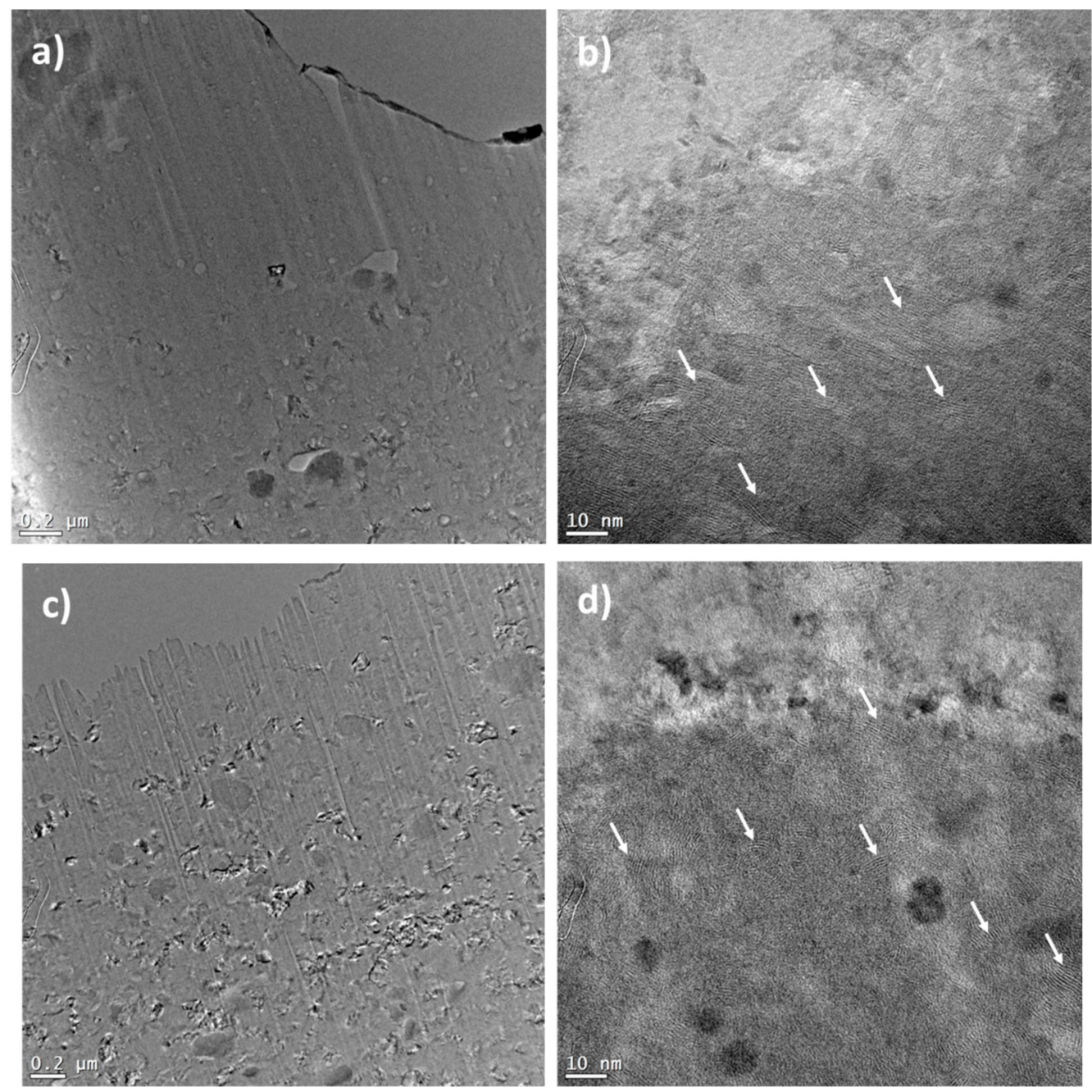

Figure 8. TEM micrographs taken at different magnifications of the MgTN_0.5h_N3 (a,b) and MgTN_3h_N3 (c,d) disks. White arrows indicate titanate nanotube sections.

Figure 9 presents the absorption kinetic curves of the Mg-based disks with different additives after $\mathrm{N}=3$ revolutions. The sample containing $\mathrm{TiO}_{2}$ reaches almost $4.5 \mathrm{wt} . \%$ hydrogen storage capacity after $4500 \mathrm{~s}$ of absorption. Interestingly, the TN-catalyzed samples have markedly different sorption properties, i.e., the specimen with $0.5 \mathrm{~h}$ co-milling (MgTN_0.5h_N3) obeys poor kinetics and capacity, since it absorbs only a very small amount of hydrogen $(\sim 0.5 \mathrm{wt} . \%)$, despite the largest lattice defect 
density of the Mg-lattice (see Figure 7c). However, when the titanate nanotubes are milled together with the Mg powder for longer durations (MgTN_3h_N3 disk), the observed kinetics and maximum storage capacity ( $4.7 \mathrm{wt} . \%$ ) seemingly exceed those of the $\mathrm{TiO}_{2}$ catalyzed sample, which means that properly dispersed TNs can effectively enhance the hydrogen storage properties of $\mathrm{Mg}$.

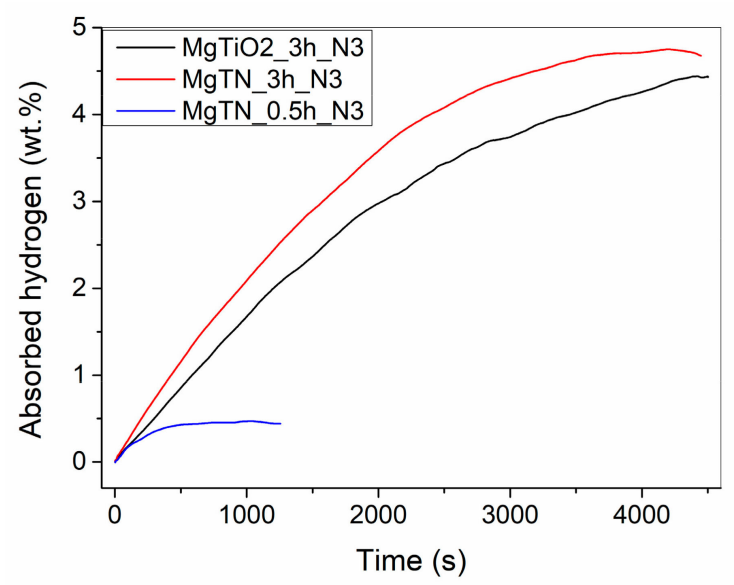

Figure 9. Absorption kinetic curves of the Mg-based composites processed by HPT for $\mathrm{N}=3$ rotations.

The significant differences obtained between the storage properties of the MgTN_0.5h_N3 and MgTN_3h_N3 disks cannot be solely related to the microstructural parameters of the hexagonal magnesium phase obtained from the CMWP analysis, since they exhibit very similar $\mathrm{D}_{\mathrm{CMWP}}$ values and comparable dislocation density throughout their radii (see Figure $7 \mathrm{a}, \mathrm{c})$. Likewise, the detected minor variation in the $\mathrm{I}(101) / \mathrm{I}(002)$ texture cannot be responsible for such distinct hydrogenation performance [40]. On the other hand, the TEM micrographs present substantial differences in the morphology and distribution of the titanate nanotube additives (see Figure 8). Therefore, we can conclude that the better dispersion of TN catalyst after $3 \mathrm{~h}$ of milling together with the Mg powder has a vital effect on the hydrogen uptake capability of the material. The defected nature of the nanotubes in the MgTN_3h_N3 disk could also be accounted for enhanced H-storage properties, due to the higher activity of destructed TN regions towards hydrogen [56].

Table 2 presents some other Mg-based hydrogen storage materials processed by HPT for comparison. As seen, the addition of titanate nanotubes to $\mathrm{Mg}$ by the combination of HEBM and HPT of the present work (MgTN_3h_N3) results in a higher hydrogen storage capability than that of pure Mg processed by HPT [57,58]. Nevertheless, the achieved capacity is somewhat lower than was obtained for $\mathrm{Mg}$ catalyzed by $\mathrm{Nb}_{2} \mathrm{O}_{5}$ powder and carbon nanotubes synthesized under similar deformation conditions [59], and therefore the extension of this investigation is required. The obtained storage capacity of our MgTN_3h_N3 disk is similar to the value of magnesium milled with $5 \mathrm{wt} . \% \mathrm{TiO}_{2}$ powder for $10 \mathrm{~h}$ [60]. Very recent works on ball-milled nanocrystalline $\mathrm{MgH}_{2}$ catalyzed by special flower-like $\mathrm{TiO}_{2}$ [61] or $\mathrm{TiO}_{2}$ nanosheet [62] additives resulted in a somewhat better hydrogenation performance.

Table 2. Comparison of different Mg-based hydrogen storage systems.

\begin{tabular}{|c|c|c|c|}
\hline Sample & Processing Route & $\begin{array}{l}\text { Hydrogen Content after } 1 \mathrm{~h} \text { of } \\
\text { Hydrogenation (wt.\%) }\end{array}$ & Ref. \\
\hline $\mathrm{Mg}$ & $\mathrm{HPT} N=10$ & 0.5 & [57] \\
\hline $\mathrm{Mg}$ & $\mathrm{HPT} N=10$ & 3.5 & [58] \\
\hline MgTN_3h_N3 & HEBM $3 h+$ HPT N $=3$ & 4.6 & this work \\
\hline $\mathrm{Mg}-\mathrm{Nb}_{2} \mathrm{O}_{5}-\mathrm{CNT}$ & HEBM $3 h+$ HPT N = 3 & 7.2 & [59] \\
\hline $\mathrm{MgH}_{2}+\mathrm{TiO}_{2}$ & HEBM $10 \mathrm{~h}$ & 4.9 & [60] \\
\hline $\mathrm{MgH}_{2}+$ flower-like $\mathrm{TiO}_{2}$ & HEBM $4 \mathrm{~h}$ & 6 & [61] \\
\hline $\mathrm{MgH}_{2}+\mathrm{TiO}_{2}$ nanosheets & HEBM 10h & 6 & [62] \\
\hline
\end{tabular}




\section{Conclusions}

The HEBM + HPT deformation route was applied to Mg powders catalyzed by titanate nanotubes (MgTN_0.5h_N3 and MgTN_3h_N3) and $\mathrm{TiO}_{2}\left(\mathrm{MgTiO} 23 \mathrm{~h} \_\mathrm{N} 3\right)$. It was shown that HPT processing can further decrease the average crystallite size of ball-milled catalyzed $\mathrm{Mg}$ (from $65-85 \mathrm{~nm}$ to $55-60 \mathrm{~nm}$ ) and can also introduce texture. In order to study the deformation-dependent microstructure of the HPT-disks, position-sensitive high-resolution XRD was carried out on the center, half-radius and edge regions of the specimens processed for $\mathrm{N}=3$ rotations. The CMWP analysis has revealed that the disks are abundant in lattice defects $\left(\sim 2 \cdot 10^{15} \mathrm{~m}^{-2}\right)$, however, the average dislocation density values do not vary significantly throughout the disks, which clearly indicates that the dynamic equilibrium between dislocation generation and annihilation is already present even after $\mathrm{N}=3$ rotations. Although the average crystallite size values are practically constant along the radii, a sharper crystallite size distribution corresponding to a more homogeneous nanostructure characterizes the edge region of the MgTN_3h_N3 disk.

It was found that the processing route considerably influences the $\mathrm{H}$-sorption, as the hydrogenation performance of the composite produced for longer co-milling of the titanate nanotubes together with $\mathrm{Mg}\left(\mathrm{MgTN} \_3 \mathrm{~h} \_\mathrm{N} 3\right)$ significantly exceeds that of MgTN_0.5h_N3. This observation can be attributed to the different morphology of the additives (better dispersed and partially damaged TN sections) and less to the microstructural parameters of the nanocrystalline $\mathrm{Mg}$ phase.

Author Contributions: Sample preparation, M.G.; preparation of titanate nanotubes, M.G., F.B., Z.N.; hydrogen storage experiments, T.S.; transmission electron microscopy, V.K.K.; HPT processing, E.S. Á.R.; writing and data evaluation, M.G., Á.R. All authors have read and agreed to the published version of the manuscript.

Funding: This work was completed in the ELTE Institutional Excellence Program (1783-3/2018/FEKUTSRAT) supported by the Hungarian Ministry of Human Capacities. Z.N. is indebted for the National Research, Development and Innovation Office for providing financial support under the Grant No. NN118172. This work was also supported by the European Regional Development Fund within the Operational Programme "Science and Education for Smart Growth 2014-2020" under the Project CoE "National center of mechatronics and clean technologies" BG05M2OP001-1.001-0008. Contribution of VKK is supported by the ÚNKP-19-4 New National Excellence Program of the Ministry for Innovation and Technology.

Conflicts of Interest: The authors declare no conflict of interest. The funders had no role in the design of the study; in the collection, analyses, or interpretation of data; in the writing of the manuscript; or in the decision to publish the results.

\section{References}

1. Yang, J.; Sudik, A.; Wolwerton, C.; Siegel, D.J. High capacity hydrogen storage materials: Attributes for automotive applications and techniques for materials discovery. Chem. Soc. Rev. 2010, 39, 656-675. [CrossRef]

2. Sahaym, U.; Norton, M.G. Advances in the application of nanotechnology in enabling a hydrogen economy. J. Mater. Sci. 2008, 43, 5395-5429. [CrossRef]

3. Ren, J.; Musyoka, N.M.; Langmi, H.W.; Mathe, M.; Liao, S. Current research trends and perspectives on materials-based hydrogen storage solutions: A critical review. Int. J. Hydrogen Energy 2017, 42, 289-311.

4. Borgschulte, A. The hydrogen grand challenge. Front. Energy Res. 2016, 4, 11.

5. Faye, O.; Szpunar, J.A. An efficient way to suppress the competition between adsorption of $\mathrm{H}_{2}$ and desorption of $\mathrm{nH}_{2}-\mathrm{Nb}$ complex from graphene sheet: A promising approach to $\mathrm{H}_{2}$ storage. J. Phys. Chem. C 2018, 122, 28506-28517. [CrossRef]

6. Hussain, T.; Mortazavi, B.; Bae, H.; Rabczuk, T.; Lee, H.; Karton, A. Enhancement in hydrogen storage capacities of light metal functionalized Borone-Graphdiyne nanosheets. Carbon 2019, 147, 199-205. [CrossRef]

7. Schlabach, L.; Zuttel, A. Hydrogen-Storage Materials for Mobile Applications. Nature 2001, 414, 353-358. [CrossRef]

8. Luo, Q.; Li, J.; Li, B.; Liu, B.; Shao, H.; Li, Q. Kinetics in Mg-based hydrogen storage materials: Enhancement and mechanism. J. Magnes. Alloys 2019, 7, 58-71. 
9. Wang, H.; Lin, H.J.; Cai, W.T.; Ouyang, L.Z.; Zhu, M. Tuning kinetics and thermodynamics of hydrogen storage in light metal element based systems-A review of recent progress. J. Alloys Compd. 2016, 658, 280-300.

10. Varin, R.A.; Czujko, T.; Wronski, Z.S. Nanomaterials for Solid State Hydrogen Storage; Springer: New York, NY, USA, 2009.

11. Aguey-Zinsou, K.-F.; Ares-Fernández, J.R. Hydrogen in magnesium: New perspectives toward functional stores. Energy Environ. Sci. 2010, 3, 526-543.

12. Crivello, J.-C.; Dam, B.; Denys, R.V.; Dornheim, M.; Grant, D.M.; Huot, J.; Jensen, T.R.; de Jongh, P.; Latroche, M.; Milanese, C.; et al. Review of magnesium hydride-based materials: Development and optimization. Appl. Phys. A 2016, 122, 97. [CrossRef]

13. Pasquini, L. The effect of nanostructure on the hydrogen sorption properties of magnesium-based metallic compounds: A review. Crystals 2018, 8, 106. [CrossRef]

14. Shao, H.; Xin, G.; Zheng, J.; Li, X.; Akiba, E. Nanotechnology in Mg-based materials for hydrogen storage. Nano Energy 2012, 1, 590-601. [CrossRef]

15. Sadhasivam, T.; Kim, H.-T.; Jung, S.; Roh, S.-H.; Park, J.-H.; Jung, H.-Y. Dimensional effects of nanostructured $\mathrm{Mg} / \mathrm{MgH}_{2}$ for hydrogen storage applications. Renew. Sustain. Energy Rev. 2017, 72, 523-534. [CrossRef]

16. Révész, Á.; Fátay, D. Microstructural evolution of ball-milled $\mathrm{MgH}_{2}$ during a complete dehydrogenation-hydrogenation cycle. J. Power Sources 2010, 195, 6997-7002. [CrossRef]

17. Fátay, D.; Révész, Á.; Spassov, T. Particle size and catalytic effect on the dehydriding of $\mathrm{MgH}_{2}$. J. Alloys Compd. 2005, 399, 237-241. [CrossRef]

18. Fátay, D.; Spassov, T.; Delchev, P.; Ribárik, G.; Révész, Á. Microstructural development in nanocrystalline $\mathrm{MgH}_{2}$ during $\mathrm{H}$-absorption/desorption cycling. Int. J. Hydrogen Energy 2007, 32, 2914-2919. [CrossRef]

19. Novakovic, J.G.; Novakovic, N.; Kurko, S.; Govedarovic, S.M.; Pantic, T.; Mamula, B.P.; Batalovic, K.; Radakovic, J.; Rmus, J.; Shelyapina, M.; et al. Influence of defects on the stability and hydrogen-sorption behavior of Mg-based hydrides. Chem. Phys. Chem. 2019, 20, 1216-1247. [CrossRef]

20. Polanski, M.; Bystrzycki, J.; Plocinski, T. The effect of milling conditions on microstructure and hydrogen absorption/desorption properties of magnesium hydride $\left(\mathrm{MgH}_{2}\right)$ without and with $\mathrm{Cr}_{2} \mathrm{O}_{3}$ nanoparticles. Int. J. Hydrogen Energy 2008, 33, 1859-1867. [CrossRef]

21. Valiev, R.Z.; Ishlamgaliev, R.K.; Alexandrov, I.V. Bulk nanostructured materials from severe plastic deformation. Prog. Mater. Sci. 2000, 45, 103-189. [CrossRef]

22. Silva, C.L.P.; Tristao, I.C.; Sabbaghianrad, S.; Torbati-Sarraf, S.A.; Figueiredo, R.B.; Langdon, T.G. Microstructure and hardness evolution in magnesium processed by HPT. Mater. Res. 2017, 20, 2-7. [CrossRef]

23. Kusadome, Y.; Ikeda, K.; Nakamori, Y.; Orimo, S.; Horita, Z. Hydrogen storage capability of $\mathrm{MgNi}_{2} \mathrm{Processed}$ by high pressure torsion. Scr. Mater. 2007, 57, 751-753. [CrossRef]

24. Révész, Á.; Kánya, Z.; Verebélyi, T.; Szabó, P.J.; Zhilyaev, A.P.; Sapssov, T. The effect of high-pressure torsion on the microstructure and hydrogen absorption kinetics of ball-milled $\mathrm{Mg}_{70} \mathrm{Ni}_{30}$. J. Alloys Compd. 2010, 504, 83-88. [CrossRef]

25. Hongo, T.; Edalati, K.; Arita, M.; Matsuda, J.; Akiba, E.; Horita, Z. Significance of grain boundaries and stacking faults on hydrogen storage properties of $\mathrm{Mg}_{2} \mathrm{Ni}$ intermetallics processed by high-pressure torsion. Acta Mater. 2015, 92, 46-54. [CrossRef]

26. Edalati, K.; Akiba, E.; Horita, Z. High-pressure torsion for new hydrogen storage materials. Sci. Technol. Adv. Mater. 2018, 19, 185-193. [CrossRef]

27. Kitabayashi, K.; Edalati, K.; Li, H.-W.; Akiba, E.; Horita, Z. Phase transformations in $\mathrm{MgH}_{2}-\mathrm{TiH}_{2}$ hydrogen storage system by high-pressure torsion process. Adv. Eng. Mater. 2019, 22, 1900027. [CrossRef]

28. Gajdics, M.; Calizzi, M.; Pasquini, L.; Schafler, E.; Révész, Á. Characterization of a nanocrystalline Mg-Ni alloy processed by high-pressure torsion during hydrogenation and dehydrogenation. Int. J. Hydrogen Energy 2016, 41, 9803-9809.

29. Révész, Á.; Gajdics, M.; Schafler, E.; Calizzi, M.; Pasquini, L. Dehydrogenation-hydrogenation characteristics of nanocrystalline $\mathrm{Mg}_{2} \mathrm{Ni}$ powders compacted by high-pressure torsion. J. Alloys Compd. 2017, 702, 84-91. [CrossRef]

30. Kumar, S.; Singh, A.; Tiwari, G.P.; Kojima, Y.; Kain, V. Thermodynamics and kinetics on nano-engineered $\mathrm{Mg}-\mathrm{MgH}_{2}$ system for reverible hydrogen storage applications. Thermochem. Acta 2017, 652, 103-108. 
31. Révész, Á.; Gajdics, M.; Spassov, T. Microstructural evolution of ball-milled Mg-Ni powder during hydrogen sorption. Int. J. Hydrogen Energy 2013, 38, 8342-8349. [CrossRef]

32. Yasuoka, S.; Ishida, J.; Kishida, K.; Inui, H. Effects of cerium on the hydrogen absorption-desorption properties of rare earth-Mg-Ni hydrogen-absorbing alloys. J. Power Sources 2017, 346, 56-62. [CrossRef]

33. Yu, H.; Bennici, S.; Auroux, A. Hydrogen storage and release: Kinetic and thermodynamic studies of $\mathrm{MgH}_{2}$ activated by transition metal nanoparticles. Int. J. Hydrogen Energy 2014, 39, 11633-11641. [CrossRef]

34. Oelerich, W.; Klassen, T.; Bormann, R. Comparison of the catalytic effects of $\mathrm{V}_{2} \mathrm{~V}_{2} \mathrm{O}_{5}, \mathrm{VN}$, and VC on the hydrogen sorption of nanocrystalline Mg. J. Alloys Compd. 2001, 322, L5-L9. [CrossRef]

35. Révész, Á.; Fátay, D.; Spassov, T. Microstructure and hydrogen sorption kinetics of Mg nanopowders with catalyst. J. Alloys Compd. 2007, 434, 725-728.

36. Barkhordarian, G.; Klassen, T.; Bormann, R. Fast hydrogen sorption kinetics of nanocrystalline Mg using $\mathrm{Nb}_{2} \mathrm{O}_{5}$ as catalyst. Scr. Mater. 2003, 49, 213-217.

37. Ruse, E.; Buzaglo, M.; Pevzner, S.; Pri-Bar, I.; Skripnyuk, V.M.; Rabkin, E.; Regev, O. Tuning Mg hydriding kinetics with nanocarbons. J. Alloys Compd. 2017, 725, 616-622. [CrossRef]

38. Zhang, X.; Leng, Z.; Gao, M.; Hu, J.; Du, F.; Yao, J.; Pan, H.; Liu, Y. Enhanced hydrogen storage properties of $\mathrm{MgH}_{2}$ catalyzed with carbon-supported nanocrystalline $\mathrm{TiO}_{2}$. J. Power Sources 2018, 398, 183-192. [CrossRef]

39. Zhao, D.-L.; Zhang, Y.-H. Research progress in Mg-based hydrogen storage alloys. Rare Met. 2014, 33, 499-510. [CrossRef]

40. Gajdics, M.; Spassov, T.; Kis, V.K.; Schafler, E.; Révész, Á. Microstructural and morphological investigations on $\mathrm{Mg}-\mathrm{Nb}_{2} \mathrm{O}_{5}-\mathrm{CNT}$ nanocomposites processed by high-pressure torsion for hydrogen storage applications. Int. J. Hydrogen Energy 2019. [CrossRef]

41. Campos, R.B.V.; Camargo, S.A.S., Jr.; Brum, M.C.; Dos Santos, D.S. Hydrogen uptake enhancement by the use of a magnesium hydride and carbon nanotubes mixture. Mater. Res. 2017, 20, 85-88.

42. Croston, D.L.; Grant, D.M.; Walker, D.S. The catalytic effect of titanium oxide based additives on the dehydrogenation and hydrogenation of milled $\mathrm{MgH}_{2}$. J. Alloys Compd. 2010, 492, 251-258. [CrossRef]

43. Oelerich, W.; Klassen, T.; Bormann, R. Mg-based hydrogen storage materials with improved hydrogen sorption. Mater. Trans. 2001, 42, 1588-1592. [CrossRef]

44. Polanski, M.; Bystrzycki, J. Comparative studies of the influence of different nano-sized metal oxides on the hydrogen sorption properties of magnesium hydride. J. Alloys Compd. 2009, 486, 697-701. [CrossRef]

45. Chen, M.; Xiao, X.; Zhang, M.; Zheng, J.; Liu, M.; Wang, X.; Jiang, L.; Chen, L. Highly dispersed metal nanoparticles on $\mathrm{TiO}_{2}$ acted as nano redox reactor and its synergistic catalysis on the hydrogen storage properties of magnesium hydride. Int. J. Hydrogen Energy 2019, 44, 15100-15109. [CrossRef]

46. Jardim, P.M.; da Conceicao, M.O.T.; Brum, M.C.; dos Santos, D.S. Hydrogen sorption kinetics of ball-milled $\mathrm{MgH}_{2}$-TTNT nanotubes with different sodium contents. J Alloys Compd. 2014, 615, S711-S714. [CrossRef]

47. Wu, X.; Jiang, Q.-Z.; Ma, Z.-F.; Fu, M.; Shangguan, W.-F. Synthesis of titania nanotubes by microwave irradiation. Solid State Commun. 2005, 136, 513-517.

48. Wong, C.L.; Tan, Y.N.; Mohamed, A.R. A review on the formation of titania nanotube photocatalysts by hydrothermal treatment. J. Environ. Manag. 2011, 92, 1669-1680. [CrossRef]

49. Williamson, G.K.; Hall, W.H. X-ray line broadening from filed aluminium and wolfram. Acta Metall. 1953, 1, 22.

50. Ribárik, G.; Gubicza, J.; Ungár, T. Correlation between strength and microstructure of ball-milled Al-Mg alloys determined by X-ray diffraction. Mater. Sci. Eng. A 2004, 387, 343-347. [CrossRef]

51. Ribárik, G.; Jóni, B.; Ungár, T. Global optimum of microstructure parameters in the CMWP line-profile-analysis method by combining Marquardt-Levenberg and Monte-Carlo procedures. J. Mater. Sci. Technol. 2019, 35, 1508-1514.

52. Estrin, Y.; Vinogradov, A. Extreme grain refinement by severe plastic deformation: A wealth of challenging science. Acta Mater. 2013, 61, 782-817. [CrossRef]

53. Xu, C.; Horita, Z.; Langdon, T.G. The evolution of homogeneity in an aluminium alloy processed using high-pressure torsion. Acta Mater. 2008, 56, 5168-5176. [CrossRef]

54. Kapoor, G.; Huang, Y.; Sarma, V.S.; Langdon, T.G.; Gubicza, J. Effect of Mo addition on the microstructure and hardness of ultrafine-grained $\mathrm{Ni}$ alloys processed by a combination of cryorolling and high-pressure torsion. Mater. Sci. Eng. A 2017, 688, 92-100. [CrossRef] 
55. Gubicza, J.; Hung, P.T.; Kawasaki, M.; Han, J.K.; Zhao, Y.; Xue, Y.; Lábár, J.L. Influence of severe plastic deformation on the microstructure and hardness of a CoCrFeNi high-entropy alloy: A comparison with CoCrFeNiMn. Mater. Charact. 2019, 154, 304-314. [CrossRef]

56. Skripnyuk, V.M.; Rabkin, E.; Bendersky, L.A.; Magrez, A.; Carreno-Morelli, E.; Estrin, Y. Hydrogen storage properties of as-synthesized and severely deformed magnesium-Multiwall carbon nanotubes composite. Int. J. Hydrogen Energy 2010, 35, 5471-5478. [CrossRef]

57. Edalati, K.; Yamamoto, A.; Horita, Z.; Ishihara, T. High-pressure torsion of pure magnesium: Evolution of mechanical properties, microstructures and hydrogen storage capacity with equivalent strain. Scr. Mater. 2011, 64, 880-883. [CrossRef]

58. Révész, Á.; Gajdics, M. Correlation between Microstructure and Hydrogen Storage Properties of Nanocrystalline Magnesium Subjected to High-Pressure Torsion. Mater. Sci. Forum 2017, 885, 67-73. [CrossRef]

59. Révész, Á.; Spassov, T.; Kis, V.K.; Schafler, E.; Gajdics, M. The Influence of Preparation Conditions on the Hydrogen Sorption of $\mathrm{Mg}-\mathrm{Nb}_{2} \mathrm{O}_{5}-\mathrm{CNT}$ Produced by Ball Milling and Subsequent High-Pressure Torsion. J. Nanosci. Nanotechnol. 2020. [CrossRef]

60. Zhang, J.; Shi, R.; Zhu, Y.; Liu, Y.; Zhang, Y.; Li, S.; Li, L. Remarkable Synergistic Catalysis of Ni-Doped Ultrafine $\mathrm{TiO}_{2}$ on Hydrogen Sorption Kinetics of $\mathrm{MgH}_{2}$. Appl. Mater. Interfaces 2018, 10, 24975-24980. [CrossRef]

61. Zhang, M.; Xiao, X.; Luo, B.; Liu, M.; Chen, M.; Chen, L. Superior de/hydrogenation performances of $\mathrm{MgH}_{2}$ catalyzed by 3D flower-like $\mathrm{TiO}_{2} @ \mathrm{C}$ nanostructures. J. Energy Chem. 2020, 46, 191-198. [CrossRef]

62. Ma, Z.; Liu, J.; Zhu, Y.; Zhao, Y.; Lin, H.; Zhang, Y.; Li, H.; Zhang, J.; Liu, Y.; Gao, W.; et al. Crystal-facet-dependent catalysis of anatase $\mathrm{TiO}_{2}$ on hydrogen storage of $\mathrm{MgH}_{2}$. J. Alloys Compd. 2020, 822, 153553. [CrossRef]

(C) 2020 by the authors. Licensee MDPI, Basel, Switzerland. This article is an open access article distributed under the terms and conditions of the Creative Commons Attribution (CC BY) license (http://creativecommons.org/licenses/by/4.0/). 